\title{
HUBUNGAN KEGUGURAN DAN ANEMIA DENGAN PERNIKAHAN USIA MUDA DI DESA HAPESONG LAMA
}

\author{
Melfi Suryaningsih ${ }^{1}$, Asfriyati ${ }^{2}$, Heru Santosa $^{2}$ \\ ${ }^{1}$ Mahasiswa Program Studi S2 Ilmu Kesehatan Masyarakat, Universitas Sumatera Utara \\ Email: melfisuryani@gmail.com \\ ${ }^{2}$ Dosen Fakultas Kesehatan Masyarakat, Universitas Sumatera Utara
}

Masuk: 14-05-2018, revisi: 06-03-2019, diterima untuk diterbitkan : 13-08-2019

\begin{abstract}
ABSTRAK
Pernikahan usia muda akan berlanjut dengan kehamilan usia muda. Akibat belum siapnya sistem reproduksi remaja untuk menerima kehamilan meningkatkan risiko untuk terjadinya komplikasi yang berpotensi meningkatkan angka kematian ibu dan bayi. Remaja dalam proses pertumbuhan dan perkembangan harus berbagi nutrisi dengan janin yang dikandungnya. Anemia kehamilan merupakan salah satu risiko yang akan dihadapi ibu hamil muda jika kebutuhan tubuh dan janinnya tidak tercukupi, selain itu keadaan psikologi remaja yang masih belum stabil dan siap dengan perubahan peran baru akan memicu terjadinya keguguran akibat stres. Tujuan penelitian adalah untuk memperoleh informasi hubungan pernikahan usia muda dengan keguguran dan anemia. Metode yang digunakan adalah Desain potong lintang, sampel 78 orang yang diambil secara simple random sampling. Pengambilan data dengan wawancara menggunakan kuesioner. Variabel terikat adalah pernikahan usia muda, variabel bebas adalah keguguran dan anemia. Analisis data dengan uji Chi Square. Hasil penelitian yaitu tidak terdapat hubungan menikah usia muda dengan keguguran tetapi terdapat hubungan yang bermakna antara pernikahan usia muda dengan anemia $(\mathrm{p}<0,05)$. Dapat disimpulkan bahwa ibu yang menikah muda berisiko mengalami anemia kehamilan dibandingkan dengan ibu yang menikah pada usia reproduksi sehat.
\end{abstract}

Kata kunci: Pernikahan usia muda; Keguguran; Anemia

\begin{abstract}
Young marriages will continue with young pregnancies. As a result of not being ready for the adolescent reproductive system to accept pregnancy increases the risk for complications that could potentially increase maternal and infant mortality. Adolescents in the process of growth and development must share nutrients with the fetus they contain. Anemia of pregnancy is one of the risks faced by young pregnant women if the body and fetal needs are not fulfilled, besides the psychological state of adolescents who are still unstable and ready for a new role change will trigger a miscarriage due to stress. The purpose of this study was to obtain information on the relationship of young marriage with miscarriage and anemia. The method used is a cross-sectional design, a sample of 78 people taken by simple random sampling. Retrieval of data by interview using a questionnaire. The dependent variable is young marriage, the independent variable is miscarriage and anemia. Data analysis with Chi Square test. The results of the study are that there is no relationship between young marriage and miscarriage but there is a significant relationship between young marriage and anemia $(p<0.05)$. It can be concluded that mothers who marry young are at risk of developing pregnancy anemia compared to mothers who marry at a healthy reproductive age.
\end{abstract}

Keywords: Young marriage; Miscarriage; Anemia

\section{PENDAHULUAN}

Berdasarkan data United Nations Department of Economic and Social Affairs (UNDESA) tahun 2011 Indonesia termasuk negara dengan persentase pernikahan usia muda tinggi di dunia (ranking 37). Posisi ini merupakan yang tertinggi kedua di ASEAN setelah Kamboja. Pada kenyataannya menurut data Riskesdas tahun 2010, perempuan muda di Indonesia dengan interval usia 10-14 tahun yang telah menikah terdapat sebanyak 0,2 persen atau lebih dari 22.000 wanita muda berusia 10-14 tahun di Indonesia sudah menikah sebelum usia 15 tahun. Pada 
interval usia yang lebih tinggi, perempuan muda berusia 15-19 yang telah menikah memiliki angka $11,7 \%$ jauh lebih besar jika dibandingkan dengan laki-laki muda berusia 15-19 tahun sejumlah 1,6\%. Sementara untuk interval usia diantara kelompok umur perempuan 20-24 tahun ditemukan bahwa lebih dari 56,2 persen sudah menikah (BKKBN,2012).

Kondisi yang fatal dan mengancam jiwa akan dialami oleh 14,2 juta anak perempuan di seluruh dunia yang menjadi pengantin usia muda setiap tahunnya selama periode 2011-2020. Perkawinan usia anak menyebabkan kehamilan dan persalinan dini, yang berhubungan dengan angka kematian ibu yang tinggi dan keadaan tidak normal bagi ibu karena tubuh anak perempuan belum sepenuhnya matang untuk melahirkan.Anak perempuan usia 10-14 tahun memiliki risiko lima kali lebih besar untuk meninggal dalam kasus kehamilan dan persalinan daripada perempuan usia 20-24 tahun, dan secara global kematian yang disebabkan oleh kehamilan dan persalinan merupakan penyebab utama kematian anak perempuan usia 15-19 tahun.

Kejadian anemia pada ibu hamil masih cukup tinggi karena sebagian besar dari mereka belum menyadari pentingnya pencegahan anemia serta bahaya yang ditimbulkan. Bahaya anemia pada kehamilan dapat menimbulkan abortus, persalinan prematur, hambatan tumbuh kembang janin dalam rahim, infeksi, dekompensasi kordis $(\mathrm{Hb}<6 \mathrm{gr} \%)$, mola hidatidosa, hiperemesis gravidarum, perdarahan antepartum, (ketuban pecah dini), saat persalinan (gangguan his dan kekuatan mengejan, kala I lama, kala II lama, retensio plasenta, atonia uteri, perdarahan post partum) dan saat nifas (sub-involusi uteri, pengeluaran ASI berkurang, anemia kala nifas, infeksi mamae). Selain itu, bahaya yang ditimbulkan terhadap janin adalah abortus, kematian intrauteri, persalinan prematuritas tinggi, Berat Badan Lahir Rendah (BBLR), kelahiran dengan anemia, dapat terjadi cacat bawaan, bayi mudah mendapat infeksi sampai kematian perinatal, dan inteligensia rendah (Manuaba et.al. 2010).

Tingginya angka kematian ibu berkaitan erat dengan anemia, baik pada saat proses kehamilan, persalinan dan menjalani masa nifas. Anemia juga menyebabkan rendahnya kemampuan jasmani karena sel-sel tubuh tidak cukup mendapat pasokan oksigen. Pada wanita hamil, anemia meningkatkan frekuensi komplikasi pada kehamilan dan persalinan. Risiko kematian maternal, angka prematuritas, berat badan bayi lahir rendah, dan angka kematian perinatal meningkat. Kelahiran prematur dari ibu yang menderita anemia gizi besi berasosiasi dengan masalah baru seperti berat badan lahir rendah, defisiensi respon imun dan cenderung mendapat masalah psikologik dan pertumbuhan. Apabila hal ini berlanjut maka hal ini berkorelasi dengan rendahnya Intelligence Quotient (IQ) dan kemampuan belajar. Semua hal tersebut mengakibatkan rendahnya kualitas sumber daya manusia, produktivitas dan implikasi ekonomi (Cunningham et al, 2013; Susiloningtyas, 2012).

SDKI tahun 2012 memperoleh angka kematian neonatal, postneonatal, bayi dan balita pada ibu yang berusia kurang dari 20 tahun lebih tinggi dibandingkan pada ibu usia 20-39 tahun Hal ini dikarenakan kematangan secara biologis yang belum sempurna dapat mengakibatkan kematian saat melahirkan. Selain itu kematangan secara pribadi juga masih belum maksimal (Kementerian Kesehatan RI, 2015).

Hasil penelitian Hartono (2012) yang dilaksanakan di Rumah Sakit Immanuel mengenai perbandingan risiko komplikasi ibu dan bayi pada kehamilan remaja dengan usia reproduksi sehat, dapat disimpulkan bahwa kelompok usia remaja memiliki peluang kejadian abortus 2 kali lebih tinggi dibandingkan dengan kelompok usia reproduksi sehat. 
Hasil penelitian Hapisah dan Rizani (2015), Rizkah dan Mahmudiono (2017) dan Rahayu, et.al (2017) kehamilan remaja memiliki hubungan yang bermakna dengan kejadian anemia pada kehamilan. Ibu hamil usia remaja beresiko mengalami anemia dua sampai empat kali dibandingkan dengan ibu hamil non remaja (usia reproduksi sehat).

Sebanyak 43,6\% ibu usia 15-49 tahun di Desa Hapesong lama melakukan pernikahan usia muda. Sedangkan pada tahun 2016 di Desa Hapesong Lama telah terjadi pernikahan pada usia remaja yaitu sebesar $15 \%$.

\section{METODE}

Jenis penelitian ini adalah penelitian survei dengan pendekatan cross sectional. Populasi penelitian ini adalah ibu yang berusia 15-49 tahun yang sudah atau pernah menikah di Desa Hapesong Lama Kecamatan Batang Toru. Sampel dalam penelitian ini adalah 78 orang ibu berusia 15-49 tahun yang sudah atau pernah menikah di Desa Hapesong Lama Kecamatan Batang Toru. Teknik sampling yang digunakan dalam penelitian ini adalah probability sampling dengan pengambilan secara acak (simple random sampling).

\section{HASIL}

Tabel 1. Distribusi Frekuensi Berdasarkan Jenis Menikah, Keguguran dan Anemia Kehamilan

\begin{tabular}{lcc}
\multicolumn{1}{c}{ Variabel } & Jumlah & Persentase \\
& $(\mathbf{n})$ & $(\%)$ \\
\hline Jenis Menikah & 35 & 44,9 \\
$\begin{array}{l}\text { a. Usia Muda }(<20) \\
\text { b. Usia Reproduksi Sehat }(\geq 20)\end{array}$ & 43 & 55,1 \\
\hline Jumlah & 78 & 100 \\
\hline $\begin{array}{l}\text { Keguguran } \\
\text { a. Ya } \\
\text { b. Tidak }\end{array}$ & 11 & 14,1 \\
\hline Jumlah & 67 & 85,9 \\
\hline $\begin{array}{l}\text { Anemia Kehamilan } \\
\text { a. Ya } \\
\text { b. Tidak }\end{array}$ & 78 & 100 \\
\hline Jumlah & 23 & 70,5 \\
\hline
\end{tabular}


Berdasarkan Tabel 1. diperoleh hasil bahwa sebanyak 35 orang $(44,9 \%)$ yang menikah pada usia muda dan sebanyak 43 orang $(55,1 \%)$ menikah pada usia reproduksi sehat. Responden yang mengalami keguguran sebanyak 11 orang $(14,1 \%)$ dan tidak mengalami keguguran sebanyak 67 orang $(85,9 \%)$, responden yang mengalami anemia sebanyak 23 orang $(29,5 \%)$ dan tidak mengalami anemia kehamilan sebanyak 55 orang $(70,5 \%)$.

Hasil penelitian diperoleh bahwa dari 11 orang ibu yang mengalami keguguran, sebanyak 8 orang $(72,7 \%)$ yang menikah pada usia muda dan 3 orang $(27,3 \%)$ yang menikah pada usia reproduksi sehat, sedangkan ibu yang tidak mengalami keguguran sebanyak 67 orang yaitu 27 orang $(40,3 \%)$ yang menikah pada usia muda dan 40 orang (59\%) yang menikah pada usia reproduksi sehat. Hasil uji statistik diperoleh $\mathrm{p}$ value $=0,056$ lebih besar dari $\alpha=0.05$ berarti tidak terdapat hubungan yang signifikan antara keguguran dengan jenis pernikahan berdasarkan usia.

Hasil penelitian diperoleh bahwa dari 23 orang ibu yang mengalami anemia kehamilan, sebanyak 15 orang $(65,2 \%)$ yang menikah pada usia muda dan 8 orang $(34,8 \%)$ yang menikah pada usia reproduksi sehat, sedangkan ibu yang tidak mengalami anemia kehamilan sebanyak 45 orang yaitu 20 orang $(36,4 \%)$ yang menikah pada usia muda dan 35 orang $(63,6 \%)$ yang menikah pada usia reproduksi sehat. Hasil uji statistik diperoleh $\mathrm{p}$ value $=0,019$ lebih kecil dari $\alpha=0.05$ berarti terdapat hubungan yang signifikan antara anemia kehamilan dengan jenis pernikahan berdasarkan usia

Analisis keeratan hubungan dua variabel diperoleh nilai OR = 3,281 (95\% CI 1,185-9,089 yang menunjukkan bahwa ibu menikah usia muda berisiko 3 kali mengalami anemia kehamilan dibandingkan dengan ibu yang menikah usia reproduksi sehat.

Tabel 2. Hubungan Keguguran dan Anemia Kehamilan dengan Ibu Menikah Usia Muda dan Ibu Usia Reproduksi Sehat di Desa Hapesong Lama Kecamatan Batang Toru Tahun 2018

\begin{tabular}{|c|c|c|c|c|c|c|c|c|}
\hline \multirow{2}{*}{ Variabel } & \multicolumn{2}{|c|}{ Usia Muda } & \multicolumn{2}{|c|}{$\begin{array}{c}\text { Usia Reproduksi } \\
\text { Sehat }\end{array}$} & \multicolumn{2}{|c|}{ Jumlah } & \multirow{2}{*}{$\begin{array}{c}\text { OR } \\
95 \% \mathrm{CI}\end{array}$} & \multirow{2}{*}{$\begin{array}{r}P \\
\text { Value }\end{array}$} \\
\hline & $\mathbf{n}$ & $\%$ & $\mathbf{n}$ & $\%$ & $\mathbf{n}$ & $\%$ & & \\
\hline Keguguran & & & & & & & 3,951 & \\
\hline & 8 & 72,7 & 3 & 27,3 & 11 & 100 & & 0,056 \\
\hline $\begin{array}{l}\text { a. Ya } \\
\text { b. Tidak }\end{array}$ & 27 & 40,3 & 40 & 59,7 & 67 & 100 & $0,961-6,244$ & \\
\hline Anemia & & & & & & & & \\
\hline Kehamilan & 15 & 65,2 & 8 & 34,8 & 23 & 100 & & 0,019 \\
\hline $\begin{array}{l}\text { a. Ya } \\
\text { b. Tidak }\end{array}$ & 20 & 36,4 & 35 & 63,6 & 45 & 100 & 1,185-9,089 & \\
\hline
\end{tabular}




\section{HASIL DAN PEMBAHASAN}

Penelitian ini menggunakan desain cross sectional yang menganalisis hubungan variabel independen dan variabel dependen dalam waktu yang sama. Hasil penelitian menunjukkan bahwa Frekuensi pernikahan usia muda pada ibu usia 15-49 tahun di Desa Hapesong Lama sebesar 44,9\% dan tidak terdapat hubungan antara keguguran dengan usia menikah ibu, sedangkan anemia kehamilan menunjukkan hasil bahwa terdapat hubungan yang signifikan dengan usia menikah ibu.

Hasil analisa statistik menemukan bahwa tidak terdapat hubungan yang signifikan antara keguguran dengan pernikahan usia muda. Hasil penelitian ini tidak sejalan dengan teori, dimana kehamilan yang terjadi pada usia muda atau remaja akan meningkatkan risiko keguguran diakibatkan oleh belum siapnya organ reproduksi remaja untuk menerima dan menjalani proses kehamilan. Selain itu keadaan psikologi ibu muda atau remaja masih belum stabil dan butuh waktu untuk mampu beradaptasi dengan prubahan-perubahan dari proses kehamilan. Akibatnya, selain tidak ada persiapan, kehamila tidak dipelihara dengan baik. Kondisi ini menyebabkan ibu menjadi stress dan meningkatkan risiko terjadinya abortus (Pribadi, et.al. 2015; Manuaba, et.al. 2010).

Umur adalah salah satu faktor yang sangat mempengaruhi kejadian abortus karena umur dapat menggambarkan kematangan organ reproduksi. Pada saat proses kehamilan terjadi pada usia reproduksi sehat, dapat dipastikan bahwa organ reproduksi telah siap menerima kehamilan dan akan berlangsung lebih baik. Walaupun hasil perhitungan statistik menunjukkan tidak adanya hubungan yang signifikan antara umur ibu dengan kejadian abortus, jumlah ibu yang mengalami keguguran lebih banyak ditemui pada kelompok ibu yang menikah pada usia muda dari pada ibu usia reproduksi sehat.

Beberapa hal yang diperkirakan menjadi alasan perbedaan hasil penelitian ini dengan teori adalah dukungan yang diperoleh ibu hamil dari keluarga. Keluarga memastikan ibu hamil agar tidak memperoleh kesulitan selama kehamilannya dan persalinannya dengan cara memastikan kesehatan ibu dan janin selama kehamilan dan persiapan persalinan melalui kunjungan antenatal care (ANC) ke fasilitas kesehatan. Karena salah satu yang menjadi determinan penentu meningkatnya angka kesakitan dan kematian ibu menurut teori Mc.Carthy dan Maine (1992) dalam Depkes (2007) adalah akses ke pelayanan kesehatan dan pemanfaatan pelayanan kesehatan termasuk didalamnya adalah pemeriksaan antenatal. Kehamilan usia muda merupakan salah satu faktor risiko terjadinya komplikasi kehamilan, persalinan dan nifas, dengan dilakukannya pemeriksaan ANC diharapkan mampu mencegah terjadinya komplikasi yang dapat meningkatkan angka morbiditas dan mortalitas ibu dan bayi.

Berbeda dengan kejadian keguguran, kejadian anemia kehamilan memiliki hubungan yang signifikan dengan usia pernikahan. Analisis keeratan hubungan dua variabel diperoleh nilai OR = 3,281 (95\% CI 1,185-9,089). Hal ini menunjukkan bahwa ibu yang menikah usia muda berisiko 3 kali mengalami anemia kehamilan dibandingkan dengan ibu yang menikah usia reproduksi sehat.

Wanita dalam usia reproduktif mengalami kehilangan zat besi ketika menstruasi. Kehilangan rata-rata darah pada saat menstruasi adalah sekitar $30 \mathrm{ml} /$ hari. Kurangnya asupan gizi kaya zat besi pada perempuan saat menstruasi memicu terjadinya anemia. Demikian juga ketika remaja putri hamil, maka kebutuhan zat gizi khususnya zat besi akan semakin meningkat, digunakan untuk pertumbuhan dan perkembangan janin. Di sisi lain, pada saat yang sama remaja putri sendiri juga mengalami fase pertumbuhan yang sangat cepat (growth spurt) dimana kebutuhan 
zat gizi untuk pertumbuhan dan perkembangannya juga tinggi, pada saat ini tubuh remaja akan berbagi nutrisi untuk perkembangan dirinya dan pertumbuhan janinnya oleh sebab itu saat terjadi kehamilan usia muda rentan mengalami anemia kehamilan.

Penyebab lain karena perubahan fisiologis selama kehamilan yaitu terjadinya peningkatan plasma yang tidak sebanding dengan peningkatan sel-sel darahnya sehingga terjadi hemodilusi atau pengenceran. Apabila anemia tidak diatasi maka akan berpotensi menimbulkan BBLR dan resiko perdarahan pada saat melahirkan maupun setelah melahirkan. Di samping itu anemia juga akan menyebabkan daya tahan tubuh rendah sehingga terjadi infeksi (Cunningham et al, 2013).

Anemia kehamilan meningkatkan frekuensi komplikasi pada kehamilan dan persalinan. Perdarahan antepartum dan postpartum lebih sering dijumpai pada wanita yang anemis dan lebih sering berakibat fatal, sebab wanita yang anemia tidak dapat mentolerir kehilangan darah. Dampak anemia pada kehamilan bervariasi dari keluhan yang ringan hingga terjadinya gangguan kelangsungan kehamilan abortus, partus imatur/prematur), gangguan proses persalinan (inertia, atonia, partus lama, perdarahan atonis), gangguan masa nifas (subinvolusi rahim, daya tahan terhadap infeksi dan stres kurang, produksi ASI rendah), dan gangguan pada janin (abortus, dismaturitas, mikrosomi, BBLR dan kematian perinatal) (Citrakesumasari, 2012).

\section{KESIMPULAN DAN SARAN}

\section{Kesimpulan}

Hasil penelitian menemukan bahwa tidak terdapat hubungan keguguran dengan pernikahan usia muda dan adanya hubungan anemia kehamilan dengan pernikahan usia muda.

\section{Saran}

Kepada tenaga kesehatan yang ada di tingkat desa dan kecamatan serta Puskesmas bekerjasama dengan Dinas Pendidikan agar melakukan penyuluhan di sekolah, khususnya sekolah menengah baik SMP atau SMA tentang dampak pernikahan usia muda. Karena pada umumnya pernikahan usia muda terjadi pada usia 17-19 tahun, yaitu usia remaja setelah lulus SMA.

Kepada Perangkat Desa Hapesong Lama dan Kecamatan Batang Toru Agar menghidupkan kembali kegiatan remaja mesjid, karang taruna, naposo nauli bulung sebagai wadah berkumpulnya remaja melakukan hal-hal positif, saling memotivasi untuk masa depan, tidak terfokus pada kegiatan berpacaran yang dapat berisiko menjadi perilaku seks bebas.

\section{UCAPAN TERIMAKASIH}

Ucapan terima kasih disampaikan kepada Kepala desa Hapesong Lama Kecamatan Batang Toru yang telah memberikan kesempatan kepada penulis untuk melakukan penelitian di wilayah ini. Terima kasih juga disampaikan kepada dosen pembimbing Dr. Asfriyati, SKM, M.Kes dan Prof. Drs. Heru Santosa, MS, Ph.D serta responden yang telah terlibat dalam penelitian ini. 


\section{DAFTAR PUSTAKA}

BKKBN. 2012. Pernikahan Dini Pada Beberapa Provinsi di Indonesia: Akar Masalah Dan Peran Kelembagaan di Daerah. Jakarta Direktorat Analisis Dampak Kependudukan Dan Keluarga Berencana Nasional.

Citrakesumasari. Anemia Gizi Masalah dan Pencegahannya. Yogyakarta. Kalika. 2012.

Cunningham, FG., Leveno, KJ., Bloom, LS., Hauth, JC., Rouse, DJ., and Spong, CY, William Obstetrics 23th Edition, Vol 1. New York: Mc Graw Hill Education. 2013.

Depkes RI. Materi Ajar Penurunan Kematian Ibu Dan Bayi Baru Lahir. Direktorat Bina Kesehatan Ibu, Direktorat Jenderal Bina Kesehatan Masyarakat, Departemen Kesehatan Republik Indonesia, Jakarta. 2007.

Hapisah dan Ahmad Rizani. Kehamilan Remaja terhadap Kejadian Anemia Di Wilayah Puskesmas Cempaka Kota Banjarbaru. Banjarmasin. 2015. Diakses 17 November 2017.

Hartono, Audylia. Perbandingan Risiko Komplikasi Ibu dan Bayi Pada Kehamilan Remaja dengan Usia Reproduksi Sehat di Rumah Sakit Immanuel Bandung Periode Mei 2009 Mei 2012. Bandung: Universitas Kristen Maranatha. 2012. Diakses 10 November 2017.

Kemenkes RI. Infodatin Stuasi Kesehatan Reproduksi Remaja. ISSN 2442-7659. 2015.

Manuaba, I.A.C. Ilmu Kebidanan Penyakit Kandungan dan Keluarga Berencana. Jakarta: EGC. 2010.

Pribadi, A., Mose. J.C., Anwar, A.D., Kehamilan Risiko Tinggi: Perkembangan, Implikasi Klinis, \& Kontroversi. Jakarta: Sagung Seto. 2015.

Rahayu, H.S.E., Purwandari, S., Wijayanti, K, 2017. Faktor Determinan dan Resiko Kehamilan Remaja Di Kecamatan Magelang Selatan Tahun Magelang. The 6th University Research Colloquium 2017 Universitas Muhammadiyah Magelang ISSN 2407-9189.2017.

Rizkah, Z. Dan Mahmudiono, T. Hubungan Antara Umur, Gravida, Dan Status Bekerja Terhadap Resiko Kurang Energi Kronis (KEK) Dan Anemia Pada Ibu Hamil. Surabaya. Amerta Nutr (2017) 72-79 73 DOI :0.2473/amnt.v1i2.2017. 72-79. 2017. Diakses 3 Februari 2018.

Susiloningtyas, I. Pemberian Zat Besi (Fe) dalam Kehamilan. Staf Pengajar Prodi DIII Kebidanan Fakultas Ilmu Keperawatan Universitas Islam Sultan Agung.Semarang. 2012. 
